\begin{tabular}{|l|l|}
\hline Postprint Version & 1.0 \\
\hline Journal website & $\underline{\text { http://isp.sagepub.com/content/59/4/342 }}$ \\
\hline Pubmed link & $\underline{\text { http://www.ncbi.nlm.nih.gov/pubmed/22392446 }}$ \\
\hline DOI & $10.1177 / 0020764012437129$ \\
\hline
\end{tabular}

This is a NIVEL certified Post Print, more info at http://www.nivel.eu

\title{
The use of outpatient mental health care services of migrants vis-à-vis Dutch natives: Equal access?
}

\author{
G. T. KoOPMANS, ${ }^{1}$ E. UITERS, ${ }^{2}$ W. DEVILLÉ ${ }^{3,4}$ AND M. FOETS ${ }^{1}$ \\ ${ }^{1}$ Institute of Health Policy and Management, Erasmus University, Rotterdam, The Netherlands \\ ${ }^{2}$ National Institute of Public Health and the Environment (RIVM), Bilthoven, The Netherlands \\ ${ }^{3}$ International and Migrant Health, Netherlands Institute for Health Services Research (NIVEL), Utrecht, \\ The Netherlands \\ ${ }^{4}$ University of Amsterdam, Amsterdam Institute of Social Sciences Research, The Netherlands
}

\begin{abstract}
Background: Although the use of outpatient mental health care services by migrants in the Netherlands has increased in recent years, whether it aligns with the need for care is unclear.

Aims: To investigate ethnic-related differences in utilization in outpatient mental health care, taking need into account, and to examine whether socio-economic or cultural barriers explain such differences.

Methods: Data for the native population was taken from the second Dutch National Survey of General Practice $(\mathrm{N}=7,772)$. An additional random sample was drawn $(\mathrm{N}=1,305)$ from four migrant groups (Surinamese, Dutch Antilleans, Moroccans and Turks) living in the Netherlands. Participants were surveyed on mental health care utilization, indicators of need, educational level, proficiency in Dutch and acculturation.

Results: Use of outpatient mental health care was about 5\% for the indigenous population. Among migrants, percentages of use ranged from 6.5\% (Moroccans) to 9.0\% (Turks). Corrected for need, however, all non-Dutch groups had a lower chance of service utilization than the native group. Acculturation predicted utilization but did not explain all ethnic-related differences; proficiency in Dutch and health beliefs were not explanatory factors.

Conclusions: In non-Dutch-speaking migrant groups, utilization is about half the level of the native Dutch, suggesting that a substantial gap exists. Our study found that acculturation only partially explains the differences.
\end{abstract}

\section{INTRODUCTION}

Little is known about the use of mental health care services by European migrants (see e.g. Claassen, Ascoli, Berhe, \& Priebe, 2005; Lindert et al., 2008) despite the higher risk of mental problems due to migration-related stress (Bhugra, 2004; Kirmayer et al., 2011). Indeed, mental health problems are more frequent among migrant groups compared to the native population (de Wit et al., 2008; Kotwal, 2010; Levecque, Lodewyckx, \& Bracke, 2009; Levecque, Lodewyckx, \& Vranken, 2007; Rodriguez Alvarez et al., 2009; Tinghog \& Carstensen, 2010). Evidence from the USA and Canada has shown that ethnic minorities do not seek mental health care as often as other groups, regardless of mental health status (Fiscella, Franks, Doescher, \& Saver, 2002; Kirmayer et al., 2007; McGuire \& Miranda, 2008). Whether this also applies to migrants in Europe is unknown, according to the latest review by Lindert et al. (2008). Little progress has been made in the field since.

A well-known framework to examine the use of and access to health care services is Andersen's Behavioural Model, which has been applied in the field of mental health care (see e.g. (Chen \& Vargas- 
Bustamante, 2011; Hatzenbuehler, Keyes, Narrow, Grant, \& Hasin, 2008; Keyes et al., 2008). Health care use in this framework is a function of: (a) predisposing factors (such as gender and age); (b) enabling factors (such as income and health insurance status); and (c) perceived and evaluated need (Andersen, 1995, 2008). 'Perceived need' is how people view their own health and experience symptoms; 'evaluated need' refers to professional medical judgement of the

person's health. Perceived need is important in ambulatory mental health care because some kind of awareness is prerequisite to seeking help (Verhaak et al., 2009).

According to Andersen, 'realized access' is the actual use of health care, and 'equitable access' is when 'need' accounts for most of health care use. If enabling or predisposing factors explain most of the difference in use between groups - natives versus migrants, for example - access is inequitable (Andersen, 1995, 2008).

In the present study we used the Andersen framework to examine differences in access to outpatient mental health care services between migrant groups and the native population in the Netherlands. Besides the classic predisposing factors (age, gender and marital status), cultural factors such as views on mental illness and expectations regarding the role of formal health care providers may contribute to differences in use of mental health care services. Migrants, especially those with a non-western background, may have a different conceptualization of mental illness and consider it primarily caused by supernatural factors, and therefore seek help from traditional healers (Snowden \& Yamada, 2005; Stein, 2000), if at all. The results of the few studies investigating the role of cultural factors in such services are equivocal and likely depend on their method (Abe-Kim et al., 2007; Berdahl \& Torres Stone, 2009; Fassaert, Hesselink, \& Verhoeff, 2009; Shin, Song, Kim, \& Probst, 2005). Most researchers have assessed cultural factors by proxy, using factors such as nativity status, length of stay in the host country, and age at immigration (Abe-Kim et al., 2007; Berdahl \& Torres Stone, 2009; Shin et al., 2005).

While socio-economic status (SES) is an enabling factor in general health care use (van Doorslaer, Masseria, Koolman, \& OECD Health Equity Research Group, 2006), it has seldom been investigated in mental health care. A lower SES, as characterizes many European migrants, may be associated with lack of financial resources, but it is mitigated by Europe's systems of universally accessible health care. A lower SES may also be associated with a lack of knowledge of available mental health care services, which can be aggravated by foreign language issues. Lack of fluency in the host language may also impede health care use because services are provided in the host language. While in Europe its influence has not been assessed (Claassen et al., 2005; Lindert et al., 2008), there is some evidence in the USA that low proficiency of the host country's language is associated with lower access to mental health care services (Fiscella et al., 2002; Sentell, Shumway, \& Snowden, 2007).

Our study focuses on the four largest non-western migrant groups in the Netherlands: Moroccans, Turks, Surinamese and Antilleans. Research in the Netherlands has shown that immigrants make use of services to a greater extent than they did in the past and that they are now over-represented in ambulatory care compared to the Dutch population (Schrier, Theunissen, Kempe, \& Beekman, 2005). Unfortunately the study did not take into account differences in need; whether access is equitable is therefore unknown. A subsequent Dutch study suggested lower access of specialized outpatient mental health care services by Turkish and Moroccan migrants when taking into account subjective psychological distress, but the differences were not significant (Fassaert, de Wit et al., 2009). Concern about whether the current level of mental health care use adequately meets the needs of migrants remains.

The aim of our study is to assess the degree to which access to ambulatory mental health care is equal for Turkish, Moroccan, Surinamese and Antillean migrants compared to the native Dutch population. To do so, we analyse the degree to which differences in use of ambulatory mental health care reflect need, predisposing factors and enabling factors.

\section{METHODS}

\section{Study population}

Data were derived from the Second National Survey of General Practice carried out in 2001-3 in the Netherlands (Westert et al., 2005). The Dutch Data Protection Authority approved the privacy regulation of the study.

A representative sample of 104 GP practices participated in the study. The socio-demographic characteristics of their collective 385,000 patients were gathered by census (response rate: 76.5\%). 
Informed consent was included (Westert et al., 2005). Random samples were drawn for participation in face-to-face interviews. The response rate of $64.5 \%$ was not selective regarding age and gender. For our study, we included persons of Dutch origin aged 18 and older $(N=7,772)$ (Uiters, Deville, Foets, \& Groenewegen, 2006).

For the largest migrant groups in the Netherlands, an additional random sample of 1,329 patients aged 18 years or older was drawn from the sample: 400 were of Turkish origin, 297 Surinamese, 370 Moroccan, and 262 Antillean. Response rates were approximately $49 \%$ and not selective regarding age or gender among Moroccans and Turks. In the Surinamese and Antillean groups, women and older people were relatively over-represented (Uiters et al., 2006). Migrant background was defined in accordance with Statistics Netherlands, i.e. at least one parent had been foreign-born (CBS, 2000).

The content of interviews conducted among the Dutch and the migrant respondents was similar. Interviews of the migrant sample included additional questions related to language and cultural factors. Respondents were interviewed at home by trained interviewers. If necessary - and it was often the case Turkish and Moroccan migrants were interviewed in their native languages.

\section{Measures}

1. The use of outpatient mental health services (the dependent variable) was measured by asking if there had been any contact in the last 12 months with mental health services (mental health care centre, psychiatric outpatient clinic, alcohol or drug-abuse clinic, psychiatric emergency centre, independent psychiatrist, psychologist, psychotherapist, sexologist or other psychosocial treatment facility). Responses were yes $(=1)$ or no $(=0)$.

2. Need indicators (independent variables) comprised three measures:

a. We used the three subscales of the Medical Outcomes 36-Item Short-Form Health Survey (SF-36) to assess 'role limitations/emotional problems' (RE), 'vitality' (VT) and 'mental health' (MH) (Ware \& Sherbourne, 1992). Scores ranged from 0 to 100, with higher scores indicating better health. Cronbach's $\alpha=0.86,0.79,0.83$, respectively.

b. Self-reported anxiety and depression were measured according to the Advisory Commission of Statistics Netherlands (van den Berg \& van der Wulp, 2003) with two single-item questions asking whether the respondent had been (i) seriously anxious or (ii) seriously depressed for at least two weeks in the past 12 months $(0=$ no $/ 1=$ yes for each question). Values were summed resulting in a variable range of $0-2$.

c. Perceived health was assessed by a single question: 'In general, would you describe your health as excellent, very good, good, poor, or very poor?' In the multivariate analysis, the variable was dichotomized into poor or very poor (0) and good, very good or excellent (1).

3. Classic predisposing characteristics (independent variables) were age, gender and marital status. Marital status had five response categories: married, registered partnership, widowed, divorced/separated and unmarried. In the multivariate analyses this was reduced to two variables: single (never married, widowed, divorced/separated) and partnered (married, officially registered partnership). Predisposing characteristics related to cultural differences included (i) a measure of orientation towards modern western values and (ii) an assessment of lay views on illness and treatment. The latter comprised two measures. First, four items, with three possible responses each (yes $(=2)$, sometimes $(=1)$, no $(=0)$ ), were used to assess respondents' beliefs about whether lifestyle and stress were main factors causing disease. The score ranged from 0 to 2 and had a moderate reliability (Cronbach's $\alpha=0.62$ ). Second, five items (with the same response categories) assessed respondents' beliefs in the healing power of nature and prayer. The score ranged from 0 to 2 and the reliability was also moderate (Cronbach's $\alpha=0.62$ ). Orientation towards modern western values was assessed with a set of 31 propositions that reflected attitudes towards secularization, emancipation and the autonomy of children. The measure was developed by the Netherlands Institute for Social Research (SCP) for application in large-scale studies (Dagevos, Gijsberts, \& van Praag, 2003). Factor and reliability analyses were performed to see whether the 31 items could be included in the analysis as a composite score; 21 items were retained whose mean score was used as a scale score with a theoretical range of 0 to 4 and good reliability (Cronbach's $\alpha=0.85$ ).

4. Enabling characteristics (independent variables): SES was first assessed by level of education, which had three categories: low (elementary school or basic vocational training), middle (high school) and high (higher vocational or academic training). Proficiency in Dutch language was included as an enabling factor and was measured by asking the degree to which respondents (i) understood Dutch and 
(ii) spoke Dutch. Possible responses were no, a little, sufficiently and well. Both variables were dichotomized ( 0 = no, a little, sufficiently; 1 = well) and then summed to represent the variable 'Dutch language proficiency; with a theoretical score of $0-2$.

\section{Analysis}

First, descriptive analyses were carried out to examine ethnic differences in the outcome variable and all the independent variables. As the outcome was measured as a binary variable and individual observations were nested within primary care practices, we used multilevel logistic regression with practice defining the level variable. Analyses were executed with the Stata procedure xtmelogit (Rabe-Hesketh \& Skrondal, 2005).

\section{[TABLE 1]}

Five models were tested. Model 1 estimated the crude logit coefficients of the non-Dutch groups. Model 2 estimated the logit coefficients adjusted for need variables. Model 3 included standard background factors (age, gender and marital status). Model 4 included educational level. Model 5 included proficiency in Dutch. Model 6 included the set of acculturation variables. Missing values were excluded from the analyses. Age, educational level, need variables, language and cultural variables were centred on their means to facilitate the interpretation of the logit coefficients. With respect to all cultural variables, the native population received a score of 0 -i.e. the effect of the cultural variables was only estimated for the migrant groups. The underlying assumption in this model was that the effect

of acculturation was homogenous for all four migrant groups. The logit coefficients of the cultural variables can be interpreted as an indication of the relative importance of these variables in explaining ethnic differences in health care use vis-à-vis the average native population.

\section{RESULTS}

Table 1 shows a summary of the main sample characteristics for each group. The native population was on average older and Moroccans and Turks especially were on average younger. Most people were partnered in the Dutch, Moroccan and Turkish groups but the majority of the Antillean and Surinamese groups were single and had more divorced or separated people than the Dutch, Moroccans and Turks.

The educational level of the native population was the highest; that of Moroccan and Turkish groups was especially low. Turks and Moroccans scored lower than Antilleans and Surinamese in Dutch-language proficiency.

The use of services in ambulatory mental health care was lowest among the native population and highest among respondents of Turkish origin. All migrant groups had lower scores on the three SF36 dimensions indicating worse health - than the native population; scores were lowest in the Turkish group. Feelings of anxiety or depression were also reported more often in all migrant groups compared to the native population. General perceived health was best among the native population.

\section{[TABLE 2 AND TABLE 3]}

Moroccans had the least tendency to consider lifestyle and stress a cause of illness. Compared to the Antilleans and Surinamese, Turkish and Moroccan migrants had higher scores regarding the role of nature and praying in illness. Finally, normative orientation was more modern among Antilleans and Surinamese than Turks and Moroccans.

In Table 2 correlations between dependent and independent variables are displayed. Variables related to need are highly interrelated and show the highest correlations with mental health care use.

Table 3 shows a summary of the results of the multilevel logistic regression analyses to predict the use of outpatient mental health care services. Crude logit coefficients showed that the Turkish group had a higher chance of using outpatient mental health services compared to the native population (Model 1).

When adjusting for the need variables (Model 2), worse health was associated with a greater chance of outpatient mental health care use, except in the case of perceived health. The difference between Turkish and Dutch respondents disappeared, and there were no differences between the native population and the other migrant groups except

for Moroccans, who were the least likely group to use outpatient mental health care services.

After adding standard predisposing variables (Model 3), older age was associated with less-frequent use of outpatient mental health care services. All non-Dutch groups were clearly less likely to use outpatient 
mental health care services than the native Dutch population, with the Moroccan group having the lowest likelihood, followed respectively by Turks, Surinamese and Antilleans.

When educational level was added (Model 4), it appeared to be a significant predictor of outpatient mental health care utilization: higher educational levels were associated with a greater likelihood of use.

Differences between native Dutch and migrant groups, however, were still observed, although to a lesser extent and with one exception: differences in the Antillean group's educational level explained differences in utilization compared to the native Dutch group. For the other three groups, educational level partly explained their comparatively low level of utilization.

Model 5 showed that proficiency in Dutch did not contribute to the explanation of mental health care utilization. (See discussion below.)

Model 6 showed that having a more modern normative orientation was predictive of mental health services use, but this was not the case for the two health belief variables. Differences in normative orientation, however, did not explain differences in utilization between migrant groups and natives except for the Turkish group. Correcting for this variable even invoked a significant difference between the Antillean and the native Dutch groups.

\section{DISCUSSION}

Although the level of utilization of outpatient mental health care seemed comparable across ethnic groups after correcting for differences in subjective need and classical predisposing factors (especially age), adjusting for differences in need revealed substantial differences between migrant groups and the native population, showing lower levels of utilization in all migrant groups (Model 2). Our results seem to partly align with Fassaert, de Wit et al. (2009) despite some methodological differences. In their study, a lower (but not significant) uptake of outpatient mental health care services was found among Turks and Moroccans compared to the Dutch when taking into account psychological distress as assessed by the Kessler Psychological Distress Scale.

Taking into account differences in educational level fully explained the difference between the Antillean and native Dutch group. While the variable reduced the differences between the native group and the Turkish and Moroccan groups, they remained significant. Unexpectedly, proficiency in Dutch was not associated with migrants' use of outpatient mental health care services.

After adjusting for differences in normative orientation, the degree of underutilization among Surinamese became more pronounced, and the difference between native Dutch and Antilleans was again significant. Such a finding suggests an interaction between normative orientation and Antillean background, but we could not provide statistical evidence (analysis not shown).

In sum, although migrants seem to catch up regarding the use of mental health care (Schrier et al., 2005), our study suggests unequal access because the use of mental health care services is partly determined by differences other than need (Andersen, 2008). This finding should be used with caution, however, because it is based on need as defined by respondents' subjective assessments of their mental health.

Because age appeared to be predictive of outpatient mental health use (older age being associated with a lower likelihood of utilization), and adjusting for age led to significant disparities in migrant groups compared to natives, we decided to analyse possible interaction effects of age and migrant status on utilization (results not shown). The results of the additional analyses did not change those previously described: all interactions appeared to be trivial and not significant. This implies that older age has an overall effect of reducing the probability of using outpatient mental health services. Adjusting for age consequently has the strongest effect on the group with the highest number of older respondents, i.e. the native Dutch group.

We only included one measure of SES, educational level, and its role was moderate. We did not include income because it was not possible to adapt it to household size. We decided to focus on educational level because it reflects financial resources as well as general health knowledge and health literacy.

Our study did not find a relationship between proficiency in the host country's native language and the use of outpatient mental health care services. Studies from the USA have provided no clear results. Both Fiscella et al. (2002) and Sentell et al. (2007) found a clear association between limited English and use of mental health services, but none was found in the study of Abe-Kim et al. (2007). Indeed, the relationship between language skills and health care use in general remains unclear (Scheppers, van Dongen, Dekker, Geertzen, \& Dekker, 2006; Smith, Chaturvedi, Harding, Nazroo, \& Williams, 2000) and has seldom been assessed in Europe, especially with respect to mental health care. While Fassaert, Hesselink et al. (2009) 
found that Dutch language ability played a central role in the use of mental health care services, it was assessed by asking whether the respondents speak Dutch with their relatives. The unclear relationship between proficiency in the language of the host country and the use of health care services might thus be the consequence of assessment measures. Cheng, Chen and Cunningham (2007) showed that speaking a language at home different from the host country (English) was a risk

factor for not receiving recommended health care services such as cancer screening, cardiovascular disease prevention and diabetes care, regardless of respondents' comfort level in speaking the host country's language. This might explain the difference between our study and that of Fassaert, Hesselink et al. (2009), whose measure of language proficiency was whether respondents spoke Dutch in their private domains rather than our less restrictive 'Do you speak (understand) Dutch?'.

A major advantage of our study is that it can be considered representative of the Netherlands, whereas previous studies were limited to the city of Amsterdam (Fassaert, de Wit et al., 2009; Ten Have \& Bijl, 1999). Moreover, Fassaert, de Wit et al. (2009) included only the two largest groups of non-western migrants in the Netherlands; our larger sample reduced power problems. A second strength is that is our interviews were conducted in the participants’ chosen language.

\section{Limitations}

Our study is not without limitations. We relied on self-reporting for both the outcome variable (mental health care use) and independent variables, which may have introduced some bias. Nevertheless, there are indications that self-reports provide valid estimates of health care use in immigrants (Reijneveld, 2000; Reijneveld \& Stronks, 2001). Also, the questionnaires had been piloted to see if migrant respondents understood the items.

The measurement of some variables can be criticized, as illustrated above regarding proficiency in Dutch. Contrary to our expectations, certain health beliefs were not associated with the use of outpatient mental health care services and did not contribute to explaining ethnic differences. Future studies should include more specific beliefs and assess certain cultural values associated with using mental health care such as stigmatization, loss of face, taboos and perceived effectiveness. In a recent European study that did not concern migrant groups, such attitudes were significantly associated with seeking mental health care services (Ten Have et al., 2010).

Future research should also investigate migrants' use of alternative or spiritual healers or other services that may be substitutes for mental health care. An older study among immigrant women in the Netherlands found that, while they did not often seek mental health care, they were more apt to use social services (Ten Have \& Bijl, 1999). Ethnic disparities in our study thus might be (partly) explained by differences in preferences.

Last, migrants may present their health complaints differently because of a cultural adversity to reporting mental health problems with a resultant inclination towards somatization (Aragona et al., 2005; Levecque et al., 2009). Because the Dutch health care system requires a GP to provide a referral for outpatient mental health care, such a situation may mask the need for mental health referrals. Indeed, we only included respondents' subjective assessment of need. Although subjective assessments are decisive in seeking health care, including information of the assessment by the referring care provider would be a relevant addition. Indeed, future research should investigate the degree to which underuse of outpatient mental health care services might be explained by differences in GPs' assessments.

\section{CONCLUSION}

To conclude, our study was the first to provide a national picture of outpatient mental health service use of different migrant groups compared to the native population. Taking self-perceived need into account, our study indicates that access is not yet equitable; that is, access appears to depend on factors other than need.

\section{Acknowledgements}

We would like to thank an anonymous reviewer for his/her thorough comments, which were very helpful to ameliorate the first draft of our manuscript.

\section{REFERENCES}

Abe-Kim, J., Takeuchi, D. T., Hong, S., Zane, N., Sue, S., Spencer, M. S., \& Alegria, M. (2007). Use of mental health-related services among immigrant and US-born Asian Americans: Results from the national Latino and Asian American study. American Journal of Public Health, 97, 91-98. 
Koopmans, G.T., Uiters, E., Devillé, W., Foets, M. The use of outpatient mental health care services of migrants vis-à-vis Dutch natives: equal access? International Journal of Social Psychiatry: 2013, 59(4), 342-350

Andersen, R. M. (1995). Revisiting the behavioral model and access to medical care: Does it matter? Journal of Health and Social Behavior, 36, 1-10.

Andersen, R. M. (2008). National health surveys and the behavioral model of health services use. Medical Care, 46, 647-653.

Aragona, M., Tarsitani, L., Colosimo, F., Martinelli, B., Raad, H., Maisano, B., \& Geraci, S. (2005). Somatization in primary care: A comparative survey of immigrants from various ethnic groups in Rome, Italy. International Journal of Psychiatry in Medicine, 35, 241-248.

Berdahl, T. A., \& Torres Stone, R. A. (2009). Examining Latino differences in mental healthcare use: The roles of acculturation and attitudes towards healthcare. Community Mental Health Journal, 45, 393-403.

Bhugra, D. (2004). Migration and mental health. Acta Psychiatrica Scandinavica, 109, 243-258.

CBS [Statistics Netherlands]. (2000). Standaarddefinitie allochtonen. Voorburg: Centraal Bureau voor de Statistiek.

Chen, J., \& Vargas-Bustamante, A. (2011). Estimating the effects of immigration status on mental health care utilizations in the United States. Journal of Immigrant and Minority Health, 13, 671-680.

Cheng, E. M., Chen, A., \& Cunningham, W. (2007). Primary language and receipt of recommended health care among Hispanics in the United States. Journal of General Internal Medicine, 22 (Suppl. 2), $283-288$.

Claassen, D., Ascoli, M., Berhe, T., \& Priebe, S. (2005). Research on mental disorders and their care in immigrant populations:

A review of publications from Germany, Italy and the UK. European Psychiatry: The Journal of the Association of European Psychiatrists, 20, 540-549.

Dagevos, J., Gijsberts, M., \& van Praag, C. (eds). (2003). Rapportage minderheden 2003: Onderwijs, arbeid en sociaal-culturele integratie [Report on minorities 2003: Education, work and social cultural integration of minorities]. The Hague: The Netherlands Institute for Social Research.

de Wit, M. A., Tuinebreijer, W. C., Dekker, J., Beekman, A. J., Gorissen, W. H., Schrier, A. C., \& Verhoeff, A. P. (2008). Depressive and anxiety disorders in different ethnic groups: A population based study among native Dutch, and Turkish, Moroccan and Surinamese migrants in Amsterdam. Social Psychiatry and Psychiatric Epidemiology, 43, 905-912.

Fassaert, T., de Wit, M. A., Verhoeff, A. P., Tuinebreijer, W. C., Gorissen, W. H., Beekman, A. T., \& Dekker, J. (2009). Uptake of health services for common mental disorders by first-generation Turkish and Moroccan migrants in the Netherlands. BMC Public Health, 9, 307. DOI: 10.1186/1471-2458-9-307.

Fassaert, T., Hesselink, A. E., \& Verhoeff, A. P. (2009). Acculturation and use of health care services by Turkish and Moroccan migrants: A cross-sectional population-based study. BMC Public Health, 9, 332. DOI: 10.1186/1471-2458-9-332.

Fiscella, K., Franks, P., Doescher, M. P., \& Saver, B. G. (2002). Disparities in health care by race, ethnicity, and language among the insured: Findings from a national sample. Medical Care, 40, 52-59.

Hatzenbuehler, M. L., Keyes, K. M., Narrow, W. E., Grant, B. F., \& Hasin, D. S. (2008). Racial/ethnic disparities in service utilization for individuals with co-occurring mental health and substance use disorders in the general population. Journal of Clinical Psychiatry, 69, 1112-1121.

Keyes, K. M., Hatzenbuehler, M. L., Alberti, P., Narrow, W. E., Grant, B. F., \& Hasin, D. S. (2008). Service utilization differences for axis I psychiatric and substance use disorders between white and black adults. Psychiatric Services, 59, 893-901.

Kirmayer, L. J., Narasiah, L., Munoz, M., Rashid, M., Ryder, A. G., Guzder, J., \& Pottie, K. (2011). Common mental health problems in immigrants and refugees: General approach in primary care. CMAJ: Canadian Medical Association Journal - Journal De l'Association Medicale Canadienne, 183, E959-E967.

Kirmayer, L. J., Weinfeld, M., Burgos, G., du Fort, G. G., Lasry, J. C., \& Young, A. (2007). Use of health care services for psychological distress by immigrants in an urban multicultural milieu. Canadian Journal of Psychiatry. Revue Canadienne De Psychiatrie, 52, 295-304.

Kotwal, A. A. (2010). Physical and psychological health of first and second generation Turkish immigrants in Germany. American Journal of Human Biology: The Official Journal of the Human Biology Council, 22, 538-545.

Levecque, K., Lodewyckx, I., \& Bracke, P. (2009). Psychological distress, depression and generalised anxiety in Turkish and Moroccan immigrants in Belgium: A general population study. Social Psychiatry and Psychiatric Epidemiology, 44, 188-197.

Levecque, K., Lodewyckx, I., \& Vranken, J. (2007). Depression and generalised anxiety in the general population in Belgium: A comparison between native and immigrant groups. Journal of Affective Disorders, 97, 229-239.

Lindert, J., Priebe, S., Penka, S., Napo, F., Schouler-Ocak, M., \& Heinz, A. (2008). Versorgung psychisch kranker Patienten mit Migrationshintergrund [Mental health care for migrants]. Psychotherapie,

Psychosomatik, Medizinische Psychologie, 58, 123-129.

McGuire, T. G., \& Miranda, J. (2008). New evidence regarding racial and ethnic disparities in mental health: Policy implications. Health Affairs (Project Hope), 27, 393-403. 
Koopmans, G.T., Uiters, E., Devillé, W., Foets, M. The use of outpatient mental health care services of migrants vis-à-vis Dutch natives: equal access? International Journal of Social Psychiatry: 2013, 59(4), 342-350

Rabe-Hesketh, S., \& Skrondal, A. (2005). Multilevel and longitudinal modeling using Stata. College Station, TX: Stata Press.

Reijneveld, S. A. (2000). The cross-cultural validity of self-reported use of health care: A comparison of survey and registration data. Journal of Clinical Epidemiology, 53, 267-272.

Reijneveld, S. A., \& Stronks, K. (2001). The validity of self-reported use of health care across socioeconomic strata: A comparison of survey and registration data. International Journal of Epidemiology, 6, 1407-1414.

Rodriguez Alvarez, E., Lanborena Elordui, N., Errami, M., Rodriguez Rodriguez, A., Pereda Riguera, C., Vallejo de la Hoz, G., \& Moreno Marquez, G. (2009). Relacion del estatus migratorio y del apoyo social con la calidad de vida de los Marroquíes en el Pais Vasco [Relationship between migrant status and social support and quality of life in Moroccans in the Basque country (Spain)]. Gaceta Sanitaria / S.E.S.P.A.S, 23 (Suppl. 1), 29-37.

Scheppers, E., van Dongen, E., Dekker, J., Geertzen, J., \& Dekker, J. (2006). Potential barriers to the use of health services among ethnic minorities: A review. Family Practice, 23, 325-348.

Schrier, A., Theunissen, J., Kempe, P., \& Beekman, A. (2005). Migranten in de ambulante ggz maken een inhaalslag [Immigrants are catching up in their access to and use of outpatient mental health services]. Tijdschrift Voor Psychiatrie, 47, 771-777.

Sentell, T., Shumway, M., \& Snowden, L. (2007). Access to mental health treatment by English language proficiency and race/ethnicity. Journal of General Internal Medicine, 22 (Suppl. 2), 289-293.

Shin, H., Song, H., Kim, J., \& Probst, J. C. (2005). Insurance, acculturation, and health service utilization among Korean-Americans. Journal of Immigrant Health, 7, 65-74.

Smith, G. D., Chaturvedi, N., Harding, S., Nazroo, J., \& Williams, R. (2000). Ethnic inequalities in health: A review of UK epidemiological evidence. Critical Public Health, 10, 375-408.

Snowden, L. R., \& Yamada, A. M. (2005). Cultural differences in access to care. Annual Review of Clinical Psychology, 1, 143-166.

Stein, D. (2000). Views of mental illness in Morocco: Western medicine meets the traditional symbolic. CMAJ: Canadian Medical Association Journal - Journal de l'Association medicale Canadienne, 163, 1468-1471.

Ten Have, M., de Graaf, R., Ormel, J., Vilagut, G., Kovess, V., \& Alonso, J. (2010) Are attitudes towards mental health help-seeking associated with service use? Results from the European Study of Epidemiology of Mental Disorders. Social Psychiatry and Psychiatric Epidemiology, 45, $153-163$.

Ten Have, M. L. T., \& Bijl, R. V. (1999). Inequalities in mental health care and social services utilisation by immigrant women. European Journal of Public Health, 9, 45-51.

Tinghog, P., \& Carstensen, J. (2010). Cross-cultural equivalence of HSCL-25 and WHO (ten) Wellbeing index: Findings

from a population-based survey of immigrants and non-immigrants in Sweden. Community Mental Health Journal, 46, 65-76.

Uiters, E., Deville, W. L., Foets, M., \& Groenewegen, P. P. (2006). Use of health care services by ethnic minorities in the Netherlands: Do patterns differ? European Journal of Public Health, 16, 388-393.

van den Berg, J., \& van der Wulp, C. (2003). Rapport van de werkgroep revisie POLS-gezondheidsenquete 1999 [Report of the study group revision POLS health questionnaire 1999]. Voorburg/Heerlen: Statistics Netherlands.

van Doorslaer, E., Masseria, C., Koolman, X., \& OECD Health Equity Research Group. (2006). Inequalities in access to medical care by income in developed countries. CMAJ: Canadian Medical Association Journal - Journal de l'Association Medicale Canadienne, 174, 177-183.

Verhaak, P. F. M., Prins, M. A., Spreeuwenberg, P., Draisma, S., van Balkom, T. J. L. M., Bensing, J. M., \& Penninx, B. W. J. H. (2009). Receiving treatment for common mental disorders. General Hospital Psychiatry, 31, 46-55.

Ware, J. E., Jr \& Sherbourne, C. D. (1992). The MOS 36-item short-form health survey (SF-36). I. Conceptual framework and item selection. Medical Care, 30, 473-483.

Westert, G. P., Schellevis, F. G., de Bakker, D. H., Groenewegen, P. P., Bensing, J. M., \& van der Zee, J. (2005). Monitoring health inequalities through general practice: The second Dutch national survey of general practice. European Journal of Public Health, 15, 59-65. 
Koopmans, G.T., Uiters, E., Devillé, W., Foets, M. The use of outpatient mental health care services of migrants vis-à-vis Dutch natives: equal access? International Journal of Social Psychiatry: 2013, 59(4), 342-350

\section{TABLES}

Table I. Sample characteristics.

\begin{tabular}{|c|c|c|c|c|c|c|}
\hline & $\begin{array}{l}\text { Dutch } \\
(n=7,772)\end{array}$ & $\begin{array}{l}\text { Moroccan } \\
(n=364)\end{array}$ & $\begin{array}{l}\text { Turkish } \\
(n=397)\end{array}$ & $\begin{array}{l}\text { Antillean } \\
(n=252)\end{array}$ & $\begin{array}{l}\text { Surinamese } \\
(n=292)\end{array}$ & p \\
\hline Mental health care use \% (yes) & 5.2 & 6.5 & 9.0 & 8.8 & 7.1 & .001 \\
\hline \multicolumn{7}{|c|}{ Need factors } \\
\hline Not limited by emotional problems $(0-100)-M(S D)$ & $90.23(25.81)$ & $82.46(35.15)$ & $75.32(39.03)$ & $80.81(36.88)$ & $83.33(34.68)$ & .000 \\
\hline Better mental health $(0-100)-M(S D)$ & $80.82(15.31)$ & $68.91(20.10)$ & $64.60(21.19)$ & $74.00(19.32)$ & $72.59(19.12)$ & .000 \\
\hline Higher vitality $(0-100)-M(S D)$ & 70.24 (18.49) & $57.00(18.66)$ & $53.75(22.13)$ & $62.39(19.81)$ & $60.83(19.86)$ & .000 \\
\hline Feelings of anxiety - depression $(0-2)-M(S D)$ & $0.20(0.51)$ & $0.37(0.69)$ & $0.4 \mathrm{I}(0.7 \mathrm{I})$ & $0.42(0.7 \mathrm{I})$ & $0.46(0.76)$ & .000 \\
\hline Good perceived health $(I-5)-M(S D)$ & $2.26(0.94)$ & $1.97(1.11)$ & $1.92(1.10)$ & $2.07(1.08)$ & $2.01(1.09)$ & .000 \\
\hline \multicolumn{7}{|l|}{ Predisposing variables } \\
\hline \multicolumn{7}{|l|}{ Age (\%) } \\
\hline 18-34 years & 20.6 & 49.5 & 53.5 & 45.0 & 28.3 & \\
\hline $35-54$ years & 41.3 & 39.5 & 34.5 & 38.5 & 49.5 & \\
\hline $55+$ years & 38.1 & II.I & 12.0 & 16.4 & 22.2 & \\
\hline \multicolumn{7}{|l|}{ Gender (\%) } \\
\hline Male & 44.9 & 47.8 & 47.5 & 36.6 & 27.6 & .000 \\
\hline \multicolumn{7}{|l|}{ Marital status (\%) } \\
\hline Unmarried & 19.5 & 16. I & 11.3 & 48.1 & 36.5 & \\
\hline Married & 65.5 & 75.7 & 71.9 & 34.7 & 33.8 & \\
\hline Registered with partner & 2.5 & 1.9 & 6.3 & 2.7 & 4.4 & \\
\hline Separated/divorced & 4.5 & 4.6 & 6.8 & 12.6 & 20.3 & \\
\hline Widowed & 8.0 & 1.6 & 3.8 & 1.9 & 5.1 & \\
\hline Health beliefs: lifestyle/stress (0-2) $-M(\mathrm{SD})$ & NA & I.4I (0.50) & $1.51(0.43)$ & $\mathrm{I} .54(0.44)$ & $1.50(0.46)$ & .000 \\
\hline Health beliefs: prayer/nature (0-2) - M (SD) & NA & $1.00(0.48)$ & $0.99(0.44)$ & $0.86(0.46)$ & $0.90(0.51)$ & .001 \\
\hline Modern normative orientation index (0-4)- $M(S D)$ & NA & $1.63(0.60)$ & $1.74(0.60)$ & $2.32(0.56)$ & $2.29(0.57)$ & .000 \\
\hline \multicolumn{7}{|l|}{ Enabling variables } \\
\hline \multicolumn{7}{|l|}{ Educational level (\%) } \\
\hline Low & 35.2 & 56.3 & 58.0 & 34.4 & 32.2 & \\
\hline Medium & 42.9 & 35.9 & 36.5 & 53.4 & 52.9 & \\
\hline High & 21.8 & 7.9 & 5.5 & 12.2 & 14.9 & \\
\hline Dutch language mastery $(0-2)-M(S D)$ & NA & $0.88(0.96)$ & $0.82(0.96)$ & $1.65(0.70)$ & $1.85(0.80)$ & .000 \\
\hline
\end{tabular}

Table 2. Correlations between dependent and independent variables.

\begin{tabular}{|c|c|c|c|c|c|c|c|c|c|c|c|c|c|}
\hline & $\mathrm{I}$ & 2 & 3 & 4 & 5 & 6 & 7 & 8 & 9 & 10 & II & 12 & 13 \\
\hline I. Mental health care use & 1.00 & & & & & & & & & & & & \\
\hline 2. Age & -.10 & 1.00 & & & & & & & & & & & \\
\hline 3. Gender: male & -.05 & NS & 1.00 & & & & & & & & & & \\
\hline 4. Not limited by emotional problems & -.23 & NS & .08 & 1.00 & & & & & & & & & \\
\hline 5. Better mental health & -.26 & -.03 & .17 & .51 & 1.00 & & & & & & & & \\
\hline 6. Higher vitality & -.20 & NS & .16 & .44 & .68 & 1.00 & & & & & & & \\
\hline 7. More feelings of anxiety/depression & .32 & -.08 & -.10 & -.37 & -.45 & -.34 & 1.00 & & & & & & \\
\hline 8. Better perceived health & -.12 & -.19 & .06 & .28 & .38 & .47 & .03 & 1.00 & & & & & \\
\hline 9. Higher educational level & .06 & -.22 & .06 & .07 & .15 & .12 & -.05 & .19 & 1.00 & & & & \\
\hline 10. Better language mastery & NS & -.04 & -.03 & .05 & .08 & .08 & NS & .08 & -.11 & 1.00 & & & \\
\hline II. More lifestyle/stress beliefs & NS & .04 & NS & -.03 & -.04 & NS & .07 & -.04 & .06 & NS & 1.00 & & \\
\hline 12. More prayer/nature beliefs & NS & .04 & NS & -.04 & -.06 & -.04 & .05 & -.05 & .14 & -.20 & .43 & 1.00 & \\
\hline 13. More modern normative orientation & .04 & -.03 & -.06 & NS & .06 & .06 & .00 & .07 & -.18 & .45 & -.05 & -.24 & 1.00 \\
\hline
\end{tabular}


Koopmans, G.T., Uiters, E., Devillé, W., Foets, M. The use of outpatient mental health care services of migrants vis-à-vis Dutch natives: equal access? International Journal of Social Psychiatry: 2013, 59(4), 342-350

Table 3. Use of outpatient mental health care as predicted by ethnic background, need indicators, traditional predisposing factors (age, gender and marital status), enabling factors (educational level, language mastery) and specific predisposing factors (cultural variables) - logit coefficients.

\begin{tabular}{|c|c|c|c|c|c|c|}
\hline & Model I & Model 2 & Model 3 & Model 4 & Model 5 & Model 6 \\
\hline Intercept & & -1.181 & -0.961 & -0.905 & -0.887 & -0.899 \\
\hline Dutch & ref. & ref. & ref. & ref. & ref. & ref. \\
\hline Moroccan & NS & -0.582 & -0.980 & -0.730 & -0.709 & -0.624 \\
\hline Turkish & 0.556 & NS & -0.745 & -0.503 & -0.462 & NS \\
\hline Antillean & NS & NS & -0.572 & NS & NS & -0.649 \\
\hline Surinamese & NS & NS & -0.675 & -0.739 & -0.849 & -1.009 \\
\hline (Not) limited by emotional problems & -0.021 & -0.005 & -0.004 & -0.004 & -0.004 & -0.004 \\
\hline (Good) mental health & -0.047 & -0.017 & -0.020 & -0.023 & -0.023 & -0.023 \\
\hline (High) vitality & -0.039 & -0.009 & -0.008 & -0.007 & -0.008 & -0.008 \\
\hline (Higher level of) anxiety/depression feelings & 1.460 & 1.078 & 1.003 & 1.023 & 1.021 & 1.026 \\
\hline (Good) perceived health & -1.010 & NS & -0.257 & -0.397 & -0.400 & -0.419 \\
\hline (Older) age & -0.028 & & -0.033 & -0.029 & -0.029 & -0.029 \\
\hline Male & -0.418 & & NS & NS & NS & NS \\
\hline Married & -0.567 & & NS & NS & NS & NS \\
\hline Separated/widow/unmarried & & & ref. & ref. & ref. & ref. \\
\hline (Higher) educational level & 0.317 & & & 0.590 & 0.584 & 0.574 \\
\hline \multirow[t]{2}{*}{ (Good) language mastery (two items) } & NS & & & & NS & NS \\
\hline & NS & & & & & \\
\hline Lifestyle - stress beliefs & NS & & & & & NS \\
\hline Prayer - nature beliefs & NS & & & & & NS \\
\hline Modern normative orientation & 0.639 & & & & & 0.466 \\
\hline Practice - SD (of intercept) & & 0.336 & 0.297 & 0.214 & 0.216 & 0.211 \\
\hline$p\left(\chi^{2}\right)$ & & .000 & .000 & .000 & .000 & .000 \\
\hline Nagelkerke & & 0.190 & 0.218 & 0.236 & 0.237 & 0.238 \\
\hline
\end{tabular}

